Res Publica Revista de Historia de las Ideas Políticas

ISSN: $1131-558 \mathrm{X}$

En torno al Thomas Münzer, teólogo de la revolución: teología y política en Ernst Bloch y Walter Benjamin (1920-1921)

María Paula Viglione ${ }^{1}$

Recibido: 30-06-2020 / Aceptado: 10-12-2020

Resumen. Este trabajo se propone analizar la relación entre teología y política en el pensamiento de Ernst Bloch y Walter Benjamin, particularmente en los inicios de la década del veinte, período en el que ambos encuentran en el mesianismo una respuesta política frente a la crisis que enfrentaba Alemania. El marco de discusión se plantea a partir de Thomas Münzer, teólogo de la revolución [1921] de Bloch, en vistas de cotejarlo con los escritos de Benjamin de la época. Se pondrá a prueba la hipótesis de que sus reapropiaciones del mesianismo convergen en sus consideraciones sobre la historia, aunque no obturan sus diferencias en relación al sujeto histórico; éstas se traducen en distancias políticas que dan cuenta del escenario heterogéneo al interior de la izquierda alemana en el período 1920-1921.

Palabras clave: mesianismo; historia; sujeto; Benjamin; Bloch.

[en] On Thomas Münzer as Theologian of Revolution: Theology and Politics in Ernst Bloch and Walter Benjamin (1920-1921)

Abstract. This work aims to analyze the relationship between theology and politics in the thought of Ernst Bloch and Walter Benjamin, particularly in the early twenties, a period in which both find in messianism a political response to the crisis faced by Germany. The framework for discussion arises from Bloch's Thomas Münzer as Theologian of Revolution [1921], in order to compare it with Benjamin's writings of the period. I will examine the hypothesis that his re-appropriations of messianism converge in his considerations about history, although they do not obstruct their differences in relation to the historical subject; these translate into political distances that account for the heterogeneous scenario within the german left in the period 1920-1921.

Keywords: Messianism; History; Subject; Benjamin; Bloch.

Sumario. Consideraciones preliminares. I. Constelaciones teológico-políticas en los primeros intercambios de Benjamin y Bloch. II. Historia y teología. III. Teología y subjetividad. Consideraciones finales. Bibliografía.

Cómo citar: Viglione, M. P. (2021). En torno al Thomas Münzer, teólogo de la revolución: teología y política en Ernst Bloch y Walter Benjamin (1920-1921). Res Publica. Revista de Historia de las Ideas Políticas, 24(2), 173-182.

\title{
Consideraciones preliminares
}

En vistas de examinar las afinidades entre teología y política en el pensamiento temprano de Ernst Bloch y Walter Benjamin, el presente trabajo sigue los lineamientos de dos planos de análisis. El primer plano es de índole filosófico-contextual: remite al escenario cultural de la intelectualidad alemana donde aparece una reacción minoritaria que encuentra en el mesianismo otra forma de salida política frente a la crisis que enfrentaba Alemania, después de la derrota de la Primera Guerra y en los inicios de la República de Weimar. En efecto, Thomas Münzer, teólogo de la revolución [1921] de Bloch y algunos escritos de Benjamin de la época, tales como "Fragmento teológico-político" [1920-1921] y "Capitalismo como religión" [1921], entre otros, son sintomáticos de la actualización de la herencia mesiánica.

El segundo plano de análisis atiende a los elementos teóricos del mesianismo judío, el milenarismo cristiano y ciertos aspectos de las tradiciones del marxismo y el anarquismo. Se observa que aquí es posible encontrar las cercanías y distancias propias de la singularidad de cada propuesta filosófica, arraigadas en la fuente común de teología y política. En efecto, la hipótesis que guía este

1 Universidad Nacional de La Plata, Argentina. mariapaulaviglione@gmail.com. 
trabajo considera que las posturas teóricas adoptadas por Benjamin y Bloch en torno a las tradiciones teológicas y sus implicancias históricas están íntimamente atravesadas por sus posicionamientos políticos. El programa marxista de Bloch y la dimensión destructiva del anarquismo del joven Benjamin no sólo se trasladan a sus reflexiones filosóficas, sino que incluso las motorizan.

Asimismo, se intenta reunir los dos planos de análisis a partir de examinar el nexo entre teología y política en tres partes. La primera parte está dedicada a una breve reconstrucción contextual de los primeros intercambios entre Benjamin y Bloch, donde se manifiesta su interés conjunto en un programa atravesado por el mesianismo. En segundo lugar, se aborda este problema a partir de las concepciones de la historia de los autores y en sintonía con las tradiciones del cristianismo y el judaísmo presentes en sus escritos. Por último, se analizan las subjetividades que intervienen en el escenario histórico expuesto en el punto anterior, haciendo especial hincapié en la construcción de la figura de Thomas Münzer no sólo desde la perspectiva blochiana, sino también desde el lugar que ocupa la dimensión subjetiva en el marco del proyecto benjaminiano.

En efecto, dilucidar los posicionamientos teóricos y políticos de Bloch y Benjamin en un momento determinado de su propia historia filosófica y del contexto intelectual alemán en el período 1920-1921 constituye el horizonte principal de este trabajo.

\section{Constelaciones teológico-políticas en primeros intercambios de Benjamin y Bloch}

los

El primer encuentro entre Benjamin y Bloch se lleva a cabo entre los años 1918 y 1919 en Suiza por intermediación de Hugo Ball. Gershom Scholem recuerda que "Benjamin se hallaba manifiestamente muy impresionado por la filosofía de Bloch" y expresa su interés por una obra en la que estaba trabajando Bloch en torno a un "sistema del mesianismo teórico"2. En función de este aliciente compartido por el mesianismo, Benjamin se dispone a la lectura de Espíritu de la utopía [1918] $\mathrm{y}$ decide escribir una reseña sobre el libro entre fines de 1919 y comienzos de $1920^{3}$. De acuerdo a los editores de su obra completa, esta reseña, junto a un texto titulado "Phantasie über eine Stelle aus dem Geist der Utopie", no se han conservado 4 . Sin embargo, en virtud de la correspondencia de Benjamin de esa época, es posible señalar algunas observaciones en relación a estos escritos perdidos.

En primer lugar, y luego de leer Espíritu de la utopía hacia septiembre de 1919, Benjamin muestra ciertas reservas en relación al libro, pero reivindica a su autor por

G. Scholem, Walter Benjamin. Historia de una amistad, Barcelona, Península, 1987, p. 89

W. Benjamin, Gesammelte Briefe I, G. Scholem y T. W. Adorno (eds.), Frankfurt am Main, Suhrkamp, 1978, p. 224.

Cf. W. Benjamin, Gesammelte Schriften I, R. Tiedemann y H. Schweppenhäuser (eds.), Frankfurt am Mein, Suhrkamp, 1991, p. 763; W. Benjamin, Gesammelte Schriften III, op. cit., p. 605; W. Benjamin, Gesammelte Schriften VII, op. cit., p. 527. trascender la obra ${ }^{5}$. Meses más tarde, hacia febrero de 1920 y después de escribir la reseña, Benjamin vuelve a mostrarse ambivalente: aunque juzga su "concepción de la filosofía" como "diametralmente opuesta" [diametral entgegengesetzt] a la propia, considera que "algunas explicaciones importantes se corresponden con mis propias convicciones" 6 .

El mismo mes en que Benjamin lee la obra, le confiesa a Ernst Schoen que sus encuentros con Bloch incitaban su interés en la actualidad política: "su conversación apuntaba a menudo a mi rechazo de toda tendencia política actual que finalmente me vi obligado a una profundización de esta cuestión que, espero, haya valido la pena" . En efecto, hacia diciembre de 1920 Benjamin se dispone a escribir un compendio sobre su "política", del que formaría parte, entre otros escritos, su reseña de Espíritu de la utopía, junto con un comentario sobre la recensión crítica "sumamente notable y esencial" de Salomo Friedlaender en torno a las "debilidades" de la obra de Bloch ${ }^{8}$.

En este marco, Scholem menciona las discusiones que mantenían con Bloch y Ball. Tanto Benjamin como Scholem guardaban ciertos recelos en torno al activismo político y el comunismo, inclinándose por "el anarquismo teocrático" como la respuesta más consistente a la política ${ }^{9}$. Como advierte Munster, en esa época y a diferencia del joven Benjamin, Bloch ya participaba del entusiasmo revolucionario de la Liga Espartaquista y el bolchevismo leninista que ingresaba en la izquierda alemana entre 1918 y $1919^{10}$. Hacia 1920, mientras Benjamin trabaja en su política, refiere a Réflexions sur la violènce [1908] de Sorel y Aufruf zum Sozialismus [1911] de Gustav Landauer como parte del material preparatorio, referencia que permite dar cuenta de la orientación anarquista y de tono crítico hacia el marxismo presente no sólo en escritos benjaminianos conservados de la época, sino también al interior de las discusiones entre intelectuales alemanes de izquierda. Asimismo, hacia enero de 1921, Benjamin juzga Politik und Methapysik de Erich Unger como "el escrito más importante sobre política de este tiempo" "Al concebir la política en términos espirituales, Unger impugna toda forma secular de la misma; no sólo rechaza el comunismo, sino

Cf. W. Benjamin, Gesammelte Briefe I, op. cit., p. 217.

Ibidem, p. 233.

Ibidem, p. 219.

Ibidem, p. 247. Marc Berdet reconstruye este proyecto del joven Benjamin y advierte que esta "trilogía política" estaría compuesta por tres partes: la primera parte titulada "El verdadero hombre político", la segunda "La verdadera política", conformada por los capítulos "Deconstrucción de la violencia" y "Teleología sin finalidad" y la tercera y última parte incluiría una crítica a Lesabéndio de Paul Scheerbart y su reseña de Espíritu de la utopía. Este proyecto no sólo quedaría inconcluso sino que, de los textos escritos, sólo se conservaría Hacia la crítica de la violencia [1921]. Cf. M. Berdet, "La trilogía política", en P. Oyarzun, C. Pérez López y F. Rodríguez (eds.), Letal e incruenta. Walter Benjamin y la crítica de la violencia, Santiago de Chile, LOM, 2017, pp. 52-53.

9 G. Scholem, Walter Benjamin. Historia de una amistad, op. cit., p. 93.

10 Cf. A. Munster, "Ernst Bloch et Walter Benjamin: éléments d'analyse d'une amitié difficile", L'Homme et la société 69-70, 1983, p. 59.

11 W. Benjamin, Gesammelte Briefe I, op. cit., p. 252. Asimismo, para la referencia a las obras leídas por Benjamin en esa época, cf. W. Benjamin, Gesammelte Schriften VII, op.cit., p.447. 
el modo en que Marx relega la esfera espiritual a mero "epifenómeno"12.

Este debate implícito entre el marxismo blochiano y el anarquismo benjaminiano se inscribe en el contexto político sobredeterminado de Alemania: el apoyo del Partido Socialdemócrata a la Primera Guerra conduce a su división y al abandono de su facción de izquierda; ésta confluye en la Liga Espartaquista, luego constituida en el Partido Comunista alemán liderado por Rosa Luxemburg y Karl Liebknecht, asesinados en enero de 1921 en el llamado Levantamiento Espartaquista. Esto implica el fracaso de la Revolución de Noviembre, el fin del Kaiserreich y la instauración de la República de Weimar, cuyo corto período democrático estará signado por crisis políticas y económicas que sentarán las bases para el ascenso del nacionalsocialismo. Con el comienzo de la República, y después de su participación en la III Internacional -la primera celebrada luego de la ruptura con el ala socialista-,el Partido Comunista alemán se alinea al leninismo y decide presentarse a elecciones, lo cual supone la salida del sector más radical que bregaba por la abolición del sistema parlamentario y mantenía una línea más crítica con el modelo soviético. La discusión latente entre Bloch y Benjamin responde precisamente a la aglutinación política de estos acontecimientos y a las diferencias entre el comunismo y el anarquismo que existían al interior de la izquierda alemana.

En esta coyuntura, ambos autores comprenden el presente en términos de crisis y oportunidad histórica, esto es, como un momento crítico pasible de bifurcarse hacia tendencias conservadoras o revolucionarias. En pos del privilegio de estas últimas, tanto Bloch como Benjamin configuran un programa que congrega teología y política por la vía de un mesianismo revolucionario, característico, según Löwy, de lo que denomina el "romanticismo anticapitalista de la intelligentsia alemana"13. El vínculo mesiánico entre redención, restauración y apocalipsis aparece interpretado políticamente como acontecimiento disruptivo que se vale del pasado oprimido para subvertir el orden social presente. No obstante, la "ambivalencia ética" del judaísmo advertida por Rabinbach, el "péndulo" oscilante entre los polos de expectativa/ acción y pesimismo/pasividad en torno al momento mesiánico, permite ilustrar la heterogeneidad política de la intelectualidad alemana ${ }^{14}$. Mientras en Bloch aparece el componente utópico y optimista en un nuevo orden social futuro, así como la potencialidad de la acción humana para forzar su advenimiento, en Benjamin cobra mayor centralidad el pesimismo melancólico, traducido en un "anarquismo teocrático" que rechaza cualquier compromiso o activismo para abrazar en cambio la violencia pura como única instancia política en el ámbito profano.

12 M. Kohlenbach, "Religion, Experience, Politics: On Erich Unger and Walter Benjamin", en M. Kohlenbach y R. Geuss (eds.), The Early Frankfurt School and Religion, Londres/New York, Palgrave Macmillan, 2005, pp. 78-79.

13 M. Löwy, Redención y utopía. El judaísmo libertario en Europa central, Santiago/Chile, Ariadna Ediciones, 2018, p. 29.

14 A. Rabinbach, In the Shadow of Catastrophe. German Intellectuals Between Apocalypse and Enlightenment, Berkeley/Los Angeles/ London, University of California Press, 1997, p. 34.
Por otro lado, además de Espíritu de la utopía, Benjamin lee una copia de la versión completa del Thomas Münzer, enviada por Bloch hacia noviembre de 1921, $\mathrm{y}$ vuelve a decepcionarse ${ }^{15}$. A pesar de esta desilusión, la reseña que escribe de Historia y conciencia de clase [1923] se presenta como una excepción. Es preciso indicar que esta obra de Lukács significa un hito teórico para la constitución del marxismo occidental y ejerce una fuerte influencia en intelectuales europeos que, como el caso de Benjamin, todavía no habían entrado en contacto con los estudios marxianos. En este respecto, se puede conjeturar que la reseña de Bloch -elogiada considerablemente por Benjamin- jugó un papel embrionario en la conversión benjaminiana al marxismo.

Hacia 1924, durante su estancia en Capri con Bloch, Benjamin depositaba sus esperanzas en el libro de Lukács y advertía:

Tan pronto como sea posible, quiero estudiar el libro de Lukács y tendría que estar equivocado si los fundamentos de mi nihilismo no se manifestaran en la discusión contraria [gegnerisch] de los conceptos hegelianos y las tesis de la dialéctica hacia el comunismo. Pero eso no me impide ver, desde mi estancia aquí, a la praxis política del comunismo (no como problema teórico sino en tanto que postura comprometida [verbindliche Haltung]) bajo una luz diferente a la de antes ${ }^{16}$.

En este mismo contexto, Benjamin conocía a Asia Lacis y recibía las "señales comunistas" que incitarían su giro político hacia al marxismo ${ }^{17}$. Este viraje será fortalecido después de su viaje a Rusia y consolidado fuertemente en la década del treinta a partir de su amistad con Bertolt Brecht.

\section{Historia y teología}

Publicado en 1921, Thomas Münzer, teólogo de la revolución utiliza un acontecimiento de la historia alemana para sobredeterminar teórica y prácticamente su potencial disruptivo en el presente. La guerra de los campesinos alemanes -acontecida entre 1524 y 1525 en un contexto de convulsión política y económica- es actualizada por Bloch en vistas de reavivar la fuerza latente hacia el comunismo e instalar, en el seno de las discusiones marxistas, el fenómeno espiritual y religioso como un componente político significativo en todo acontecimiento revolucionario.

En efecto, el eje vertebrador de la obra reside en una nueva concepción política de la historia. Regida por "el retorno de los muertos", esta concepción trasciende lo histórico para encarnar "la plenitud testimonial [Zeug-

15 Cf. W. Benjamin, Gesammelte Briefe I, op. cit., p. 284. Según Scholem, en esa época sus relaciones comenzaron a hacerse "delicadas"; las declaraciones de Benjamin oscilaban "entre la admiración ante la fuerza que actuaba en Bloch y ante su enorme potencia intelectual, y la profunda decepción que a menudo le deparaba su obra literaria”. G. Scholem, Walter Benjamin. Historia de una amistad, op. cit., p. 117.

16 W. Benjamin, Gesammelte Briefe I, op. cit., p. 355.

17 Ibidem, p. 368. 
enfülle] referida a la revolución y al apocalipsis"18. Se trata de hacer de la historia un "palimpsesto": superponer sus capas en función del principio de "la historia subterránea de la Revolución" y recoger su legado de confluencia entre "el marxismo y el sueño de lo absoluto en una misma singladura y un mismo plan de operaciones"19. Esta tradición revolucionaria abarca desde el cristianismo primitivo, Montano, el joaquinismo y la herejía taborita, hasta la Revolución inglesa de 1648, la Revolución Francesa, la Revolución alemana de 1848 y la Revolución bolchevique. Pese a la heterogeneidad de coyunturas, Bloch construye una herética ideológica articulada en torno al principio milenarista: el regreso romántico al comunismo del cristianismo primitivo, los aspectos apocalípticos del mesianismo judío, la instauración marxista de una sociedad sin clases y la idea rectora de libertad inherente al liberalismo político. El objetivo de esta articulación no es sino traer el pasado insurrecto al presente y asumir la latencia de un espíritu utópico que, aunque no pudo ser, conserva la potencialidad de ser actualizado.

Asimismo, la obra busca resignificar el lugar de Alemania dentro de esta historia de insurrecciones: "de manera general puede considerarse que Münzer y el movimiento anabaptista constituyen ciertamente la izquierda desde un punto de vista político" 20 . $\mathrm{Al}$ atender al aliciente religioso que interviene en este acontecimiento, su envergadura política no puede ser analizada sólo desde el contexto económico ${ }^{21}$. Bloch no se apropia aquí de la respuesta leninista de la revolución bolchevique como "el eslabón más débil", esto es, no intenta demostrar cómo es posible el triunfo de una revolución comunista en un país que, carente de capitalismo desarrollado, sólo contaba con un desarrollo industrial en ciernes pero cuya base productiva era principalmente feudal. Para Bloch las condiciones productivas de la economía alemana de la época son necesarias pero no suficientes.

En sintonía con los aportes de Weber, Bloch pondera el "curso «histórico-filosófico» de lo espiritual y religioso" como un elemento central para comprender la re-

18 E. Bloch, Thomas Münzer, teólogo de la revolución, Madrid, Ciencia Nueva, 1968, p 16.

\section{Ibidem, p. 254}

Ibidem, p. 125.

Bloch recapitula: hacia 1400, el proceso de activación económica vinculado al surgimiento de las ciudades significó una "regresión acelerada" en Alemania en virtud del fortalecimiento del capital principalmente mercantil-y el aumento de poder del principado. La nobleza cedió su autonomía al principado a cambio de una mayor explotación sobre los campesinos, la posesión de la renta territorial y el excedente agrario, agudizando así las diferencias entre las capas sociales alemanas. Aunque este desarrollo incrementó el poder de los soberanos y de la burguesía, no implicó una centralización de los intereses nacionales como en el caso de Francia e Inglaterra. El atraso económico de Alemania sólo logró articular intereses en torno a algunos centros locales, generando una fragmentación política y una autonomización de las provincias que derivó en el desmoronamiento del Imperio, cuyo intento de supervivencia consistió en la explotación campesina. Frente a la disgregación de la estructura orgánica de la sociedad, estallaron disturbios campesinos a lo largo de todo el siglo XV -como el Bundschuh Bewegung en el sudoeste alemán o las guerras husitas en Bohemia- que, aunque carentes de un programa en común, reclamaban principalmente el derecho a la posesión y explotación de las tierras en regímenes comunales. Estos disturbios decantan finalmente en la guerra de los campesinos alemanes entre 1524 y 1525 , con efectos en los territorios de Austria y Suiza. Ibidem, pp. 62-63. vuelta campesina y así evitar que su carácter originario sea reducido al "plano de lo puramente ideológico"22. Si bien Marx concede al curso espiritual al menos "una realidad de estímulo" [Realität des Antriebs], Bloch interpreta que fue el espíritu positivista de su época el responsable de restringir el comunismo a la economía política y privarlo del alcance originario de la teología y su idea milenarista ${ }^{23}$. Posicionándose en contra del reduccionismo economicista que imperaba en las filas del marxismo a partir de la II Internacional, Bloch introduce en su análisis los impulsos anímicos y espirituales que intervienen en todo evento revolucionario. Este enfoque es la condición de posibilidad no sólo de salvar tradiciones políticamente divergentes, sino incluso de igualar períodos históricos tan disímiles entre sí.

Podría decirse que esta concepción blochiana de la historia converge, al tiempo que diverge, del planteo del joven Benjamin. La profanación política de la teología por la vía de una temporalidad que transforme el pasado en disrupción para el presente constituye el principal punto de acercamiento entre ambos pensadores. En el "Fragmento teológico-político" [1920-1921] -título otorgado por Theodor Adorno-, Benjamin ilustra su "concepción mística de la historia" a través de la imagen de una flecha que hacia una dirección designa el "orden de lo profano" y hacia la otra la "intensidad mesiánica": es a partir del choque entre estas fuerzas que puede generarse la interrupción temporal y así lo profano devenir en una categoría de aproximación hacia el reino mesiánico ${ }^{24}$.

Benjamin inicia el "Fragmento" con una crítica a la teleología cristiana que concibe "el Reino de Dios" como "el telos de la dynamis histórica", imposibilitando así todo vínculo entre lo religioso y lo político. Por el contrario, para Benjamin "desde el punto de vista histórico, el Reino de Dios no es meta [Ziel], sino que es final [Ende $]^{\prime 25}$. No se trata, entonces, del advenimiento de Dios en términos de una escatología trascendente y conclusiva, sino del advenimiento de su posibilidad que provoca una interrupción en el continuum histórico. Precisamente aquí Benjamin reconoce el mérito de Espiritu de la utopía de "haber negado con toda intensidad el significado político de la teocracia" 26 .

En esta línea, el gesto salvífico de las experiencias pasadas obedece, tanto en Bloch como en Benjamin, no sólo al contexto histórico de crisis, sino también al rol central que ocupa el mesianismo judío en sus obras. El componente redentor del pasado forma parte de la mística judía del "tikkun": según Scholem, consiste en "la recomposición del estadio armónico del mundo", identificado en la cábala luriana con el "mundo mesiánico" como "un momento estrictamente utópico", es decir, situado en un pasado no fáctico sino más bien en uno

\section{Idem.}

Ibidem, p. 67.

W. Benjamin, Obras, Libro II, vol. 1, R. Tiedemann y H. Schweppenhäuser (eds.), Madrid, Abada, 2007, p. 207.

Ibidem, p. 206

26 Idem. Para un análisis crítico sobre esta mención a Geist der Utopie, cf. A. Deuber-Mankowsky, "Walter Benjamin's Theological-Political Fragment as a response to Ernst Bloch's Spirit of Utopia”, Leo Baeck Institute Yearbook 47/1, 2002, pp. 3-20. 
transformado por el imaginario ${ }^{27}$. Así, ambos autores se hacen eco de esta idea de redención como el restablecimiento de ese momento originario y utópico del pasado que sólo se efectúa con el advenimiento del Mesías.

No obstante, Benjamin no proyecta este advenir disruptivo del pasado hacia el futuro, ni tampoco lo enmarca en un programa político como hace Bloch. Aunque ambos autores, influidos por el mesianismo judío y las vivencias de la Primera Guerra, redireccionan la esperanza hacia el pasado sin deslegitimarlo por los fracasos acontecidos, Bloch sigue delineando su confianza política hacia un comunismo venidero, mientras el joven Benjamin desconfía del futuro y más aún de cualquier programa que involucre un activismo político ${ }^{28}$. El posicionamiento nihilista que aparece hacia el final del "Fragmento" se explica, de acuerdo a Steiner, en función de la limitación benjaminiana de la política al orden de lo profano: en él sus objetivos se tornan nulos y sin efecto $^{29}$.

En primer lugar, es posible explicar esta distancia temporal a partir de los aportes de Agamben en torno a la figura del profeta y a los "dos tipos opuestos de nabi"30. Mientras la propuesta de Bloch se inscribiría en la categoría clásica del profeta orientado hacia el futuro, el programa de Benjamin se encauzaría hacia el pasado, es decir, como "un profeta vuelto hacia atrás", tal como definirá el "sentido esotérico" de su labor historiográfica en Sobre el concepto de historia [1940] $]^{31}$.

Ahora bien, la diferencia entre la "militancia optimista" de Bloch y "la melancolía revolucionaria y el nihilismo" de Benjamin constituye más bien un aspecto político de sus posicionamientos en torno al advenimiento mesiánico como consumación del proceso histórico ${ }^{32}$. Por un lado, la interpretación de Bloch de la revuelta campesina como parte del palimpsesto revolucionario supone una determinación empírica del tiempo histórico que es rechazada por Benjamin. De acuerdo a él, "la fuerza determinante de la forma histórica del tiempo no puede ser captada (...) ni se recoge tampoco plenamente en ningún acontecimiento empírico concreto" ${ }^{\prime 3}$. En efecto, la consumación del tiempo histórico es algo "empíricamente indeterminado": la "idea" del tiempo mesiánico, es decir, la idea de una temporalidad imprevisible y demoledora del estado de cosas. Esta tarea me-

27 G. Scholem, Conceptos básicos del judaísmo, Madrid, Trotta, 2008, p. 112 .

28 Si bien Bloch retoma las experiencias del pasado, son múltiples las alusiones a lo profético y a una dimensión del futuro no circunscrita a la idea de progreso. Cf. E. Bloch, Thomas Münzer, teólogo de la revolución, op. cit., p. 208.

29 U. Steiner, Walter Benjamin, Stuttgart/Weimar, J.B. Metzler, 2004, p. 76.

30 G. Agamben, El tiempo que resta. Comentario a la carta a los Romanos, Madrid, Trotta, 2006, p. 66.

31 W. Benjamin, La dialéctica en suspenso. Fragmentos sobre historia, Santiago de Chile, ARCIS-LOM, 2005, p. 85. La distinción entre el eje benjaminiano en el pasado y la praxis blochiana hacia el futuro es abordada por Naishtat. Cf. F. Naishtat, "Catástrofe y esperanza. Pensar un presente barroco a partir de Benjamin y Bloch", en E. Jozami, A. Kaufman, y M. Vedda (comps.), Walter Benjamin en la ex ESMA, Buenos Aires, Prometeo, 2013, pp. 251-268.

32 Las expresiones entre comillas son tomadas de: I. Boldyrev, Ernst Bloch and His Contemporaries. Locating Utopian Messianism, Londres/New York, Bloomsbury, 2014, pp. 123 y 159.

33 W. Benjamin, Obras, Libro II, vol. 1, op. cit., p. 138. siánica tiene en Benjamin el signo de lo que no puede ser dado; se trata de una consumación o cumplimiento [Erfüllung] que se ubica por fuera del ámbito intencional y del escenario profano de la historia ${ }^{34}$. En contraste, si bien para Bloch el advenimiento mesiánico también se trata de una instancia venidera por fuera de este mundo, la profanación marxista de su teología interpreta este momento revolucionario como una tarea realizable en un presente-futuro a partir de la acción política.

En su intercambio epistolar con Benjamin, Scholem expresa ciertas reservas en torno al tratamiento de Bloch de las cuestiones judaicas y aquél coincide "plenamente" [völlig] con su crítica ${ }^{35}$. Es interesante mencionar aquí su reproche a la indistinción entre el judaísmo y el cristianismo, un aspecto presente también en su Thomas Münzer. El "sincretismo" de Bloch -advierte Munsterestá en sintonía con la crítica al judaísmo ortodoxo y su rechazo a integrar elementos del "cristianismo herético" y del "profetismo"; si esta línea blochiana chocaba con el programa del sionismo de contrarrestar las tendencias de asimilación, Benjamin, en cambio, "era más sensible al renacimiento del judaísmo" sionista que buscaba acentuar la "ruptura" con el mundo cristiano ${ }^{36}$.

"Capitalismo como religión" [1921] es otro escrito de Benjamin que puede ser leído a la luz de sus vínculos con Bloch. Su mismo título alude directamente al Thomas Münzer, en particular al capítulo dedicado a Calvino ${ }^{37}$. Bloch critica allí la "ideología del dinero" del calvinismo y explica su doble operación de desprenderse del cristianismo - principalmente de su procedencia primitiva-y, al mismo tiempo, "establecer los elementos de una «religión» nueva, a saber, el capitalismo, entendido éste como religión [Kapitalismus als Religion] y como iglesia de Mammón"38. Al igual que Thomas Münzer, este escrito se hace eco de los estudios weberianos sobre la formación religiosa del capitalismo. No obstante, da un paso más: define al capitalismo como un "fenómeno esencialmente religioso"39. En este respecto, Hamacher interpreta que el diagnóstico de Bloch es más "moderado"; se trata de "una regresión al esquema de culpa pseudocristiano, del cual la Reforma -y sobre todo Münzer- debía ser la liberación". En contraste, más que la deserción del cristianismo, para Benjamin el capitalismo es la metamorfosis de su "verdadera forma"

34 Sobre la cuestión del Erfüllung en el joven Benjamin, cf. M. Sagnol, Tragik und Trauer. Walter Benjamin, Archäologe der Moderne, Berlin, Kadmos, 2017, pp. 55-58. Asimismo, sobre el signo mesiánico como lo que no puede ser dado, cf. P. Fenves, The Messianic Reduction. Walter Benjamin and the Shape of Time, California, Stanford University Press, 2011, pp. 76-78.

35 W. Benjamin, Gesammelte Briefe I, op. cit., p. 234. Para las críticas de Scholem a la sección sobre los judíos de Espiritu de la utopía, cf. G. Scholem, Walter Benjamin. Historia de una amistad, op. cit., pp. 97-99.

36 A. Munster, "Ernst Bloch et Walter Benjamin: éléments d'analyse d'une amitié difficile", op. cit., p. 63.

37 Cf. U. Steiner, "Kapitalismus als Religion. Anmerkungen zu einem Fragment Walter Benjamins", Deutsche Vierteljahrsschrift für Literaturwissenschaft und Geistesgeschichte, Band 72, 1998, pp. 147171; W. Hamacher y K. Wetters, “Guilt History: Benjamin's Sketch "Capitalism as Religion»", Diacritics 32, 3/4, 2002, p. 88.

38 E. Bloch, Thomas Münzer, teólogo de la revolución, op. cit., p. 151.

39 W. Benjamin, "El capitalismo como religión", Katatay X, 13/14, 2016, p. 187.

40 W. Hamacher y K. Wetters, “Guilt History: Benjamin’s Sketch «Capitalism as Religion»", op. cit., p. 88. 
El capitalismo se caracteriza por ser una "pura religión de culto", vaciada de todo dogma y teología. Su mitología eterniza esta práctica cultual y no sólo obtura la posibilidad de expiar su culpa, sino que incluso la engendra: en virtud del mecanismo universalizador de la Schuld, según Benjamin, no cabe encontrar una salida al capitalismo por la vía reformista, ni por la vía de abdicación, ni por la vía marxista acogida por Bloch. Ahora bien, es en la "ambigüedad demoníaca" [dämonische Zweideutigkeit] del término "Schuld" -alude tanto a la idea de culpa religiosa como de deuda económica-donde se entrevé el vínculo parasitario entre capitalismo y cristianismo ${ }^{41}$. En esta imagen del capitalismo como "parásito" [Parasit $]$ del cristianismo se condensa, siguiendo a Vargas, la principal crítica de Benjamin al esquema "causal" que utiliza Weber para explicar el vínculo entre ambos ${ }^{42}$.

Esta crítica podría aplicarse a la interpretación de Bloch: no sólo por retomar la lectura de Weber, sino incluso por extender el carácter emancipador a determinadas corrientes del cristianismo que Benjamin niega. En esta línea, Löwy señala que en las notas preparatorias a las tesis, "Benjamin parece rechazar la posibilidad de que la guerra de los campesinos sirva de referencia histórica a las luchas obreras modernas" $\mathrm{y}$, si bien no refiere a los análisis de Bloch o Engels, sí remite a la obra Geschichte des Bauernkrieges [1856] de Zimmerman ${ }^{43}$. En contraste, Bloch rescata positivamente la obra de Zimmerman ubicándola en una línea similar al análisis de Engels en Der deutsche Bauernkrieg [1850], aunque se distancia de las interpretaciones de ambos en torno a la figura de Münzer.

La referencia hacia el final del escrito a Réflexions sur la violènce [1908] de Sorel, habilita traer a escena Hacia la crítica de la violencia [1921], ensayo que constituiría "la pieza central del gran estudio sobre política" y el único que se ha conservado de sus textos políticos proyectados en esa época ${ }^{44}$. Benjamin le había enviado una copia de esta obra a Bloch y éste, por su parte, la versión completa de su Thomas Münzer unos meses después ${ }^{45}$. Podría indicarse que en ambos escritos aparece el uso legítimo de una violencia subversiva en contraposición a la violencia mítica del dispositivo estatal. Bloch distingue entre el "estatismo del régimen despótico" y la "revuelta", consignando respectivamente la "violencia maligna" del orden jurídico estatal y un "postulado de amor por la violencia" en función de la "toma de posesión, por fuerza violenta, de los medios de producción" 46 . Benjamin, por su parte, distingue entre una "violencia mítica" y una "violencia divina": mientras la primera "instaura derecho" e "inculpa", la segunda no sólo "aniquila" el derecho y "redime", sino que

${ }^{41}$ W. Benjamin, "El capitalismo como religión”, op. cit., p. 188.

42 M. Vargas, "Comentario a "Capitalismo como religión» de Walter Benjamin", op . cit., p. 392.

43 M. Löwy, Walter Benjamin: aviso de incendio. Una lectura de las tesis "Sobre el concepto de historia", Buenos Aires, Fondo de Cultura Económica, 2012, p. 70. Para la referencia a la obra de Zimmerman en las anotaciones a las tesis, cf. W. Benjamin, La dialéctica en suspenso. Fragmentos sobre historia, op. cit., p. 84.

44 U. Steiner, Walter Benjamin, op. cit., p. 78.

45 Cf. W. Benjamin, Gesammelte Briefe I, op. cit., pp. 261 y 284.

46 E. Bloch, Thomas Münzer, teólogo de la revolución, op. cit., p. 140. es definida como "violencia revolucionaria" y en radical oposición a toda pretensión mítico-fundacionalista ${ }^{47}$.

Sin embargo, la instancia exterior al círculo de la violencia que propone Bloch por la vía marxista -aun cuando el nuevo orden social se oponga a toda instancia estatal o verticalista- se distancia de la postura de Benjamin. A partir de las extensas citas que hace Benjamin de Sorel, menciona su rechazo no sólo a cualquier programa delineado desde el Estado, sino también a "cualquier tipo de programas y utopías"48. En un fragmento de la misma época, Benjamin subraya "la importancia de la anarquía para la región profana": en contraste con el "catolicismo" en cuanto "teocracia falsa, terrenal" [(falsche, irdische) Theokratie], lo divino sólo puede manifestarse en la "destrucción" y en la "violencia revolucionaria" como únicas instancias de la política en el orden profano ${ }^{49}$.

\section{Teología y subjetividad}

Haciendo uso del género biográfico, la primera parte del Thomas Münzer está destinada a la figura del teólogo revolucionario que implosiona el espíritu de revuelta de los campesinos alemanes. En sus escritos, Münzer se presenta como un impulsor ideológico de la distribución igualitaria de tierras en favor de las mayorías trabajadoras y sumamente crítico con la burguesía terrateniente y la opulencia noble y eclesiástica: “es el mayor escándalo en la tierra que nadie quiera hacerse cargo de los pobres y desamparados; los grandes de este mundo hacen todo lo que se les antoja", pues no sólo "se apropian de toda criatura" sino que "desuellan y explotan al pobre labriego y artesano y a todo ser viviente" y se auto-exceptúan de los mismos mandamientos que predican ${ }^{50}$. Asimismo, su rechazo al monopolio espiritual de la fe por parte de los sacerdotes, lo conduce a celebrar las misas en lengua alemana y elaborar una fenomenología ascética de preparación para acceder a Dios, no circunscrita sólo a letrados o eclesiásticos. A la par que admite su espíritu "subversivo" y firma sus escritos autoproclamándose como "el del martillo", exhibe cierto carácter predilecto y sectario propio del tono profético de sus manifiestos y sermones.

Ahora bien, pese a que las revueltas campesinas en las que participa Münzer no tienen un programa político articulado, la figuración blochiana del teólogo como un revolucionario comunista no persigue el propósito de la fidelidad histórica, sino la recuperación del espíritu subversivo del pasado alemán para inscribirlo en la coyuntura del presente. De este modo, la configuración que hace Bloch del Münzer histórico está directamente atravesada y absorbida por el principio revolucionario y milenarista: "en cuanto fenómeno y concepto, Münzer

\footnotetext{
W. Benjamin, Obras, Libro II, vol. 1, op. cit., p. 202.

4 Ibidem, p. 198. La crítica benjaminiana a la idea de "programa" como praxis política continúa en la década del treinta al identificarla con el proceder de la "clase burguesa". Cf. W. Benjamin, Gesammelte Schriften IV, op. cit., pp. 816-817.

49 W. Benjamin, Gesammelte Schriften VI, op. cit., pp. 98-99.

50 E. Bloch, Thomas Münzer, teólogo de la revolución, op. cit., pp. 54-55.
} 
queda determinado al fin enteramente en virtud del curso y resultado, del contenido conflictivo y la idea de la gran revolución alemana" ${ }^{\text {. }}$.

Podría advertirse sobre dos puntos problemáticos alrededor de la construcción de Münzer. En primer lugar, la definición de la vida y la praxis münzeriana como "la trayectoria de un mártir"; su fracaso -como símbolo subjetivado del fracaso de los campesinos alemanesaparece como "figura plenamente representativa, canónica y trágica” de una revolución que no pudo $\operatorname{ser}^{52}$. En este respecto, es sugestiva la definición de Infranca en torno al Münzer de Bloch como "máscara trágica" del Münzer histórico. El intérprete subraya la conversión blochiana de Münzer y la guerra campesina en $\mu \tilde{v} \theta$ o y

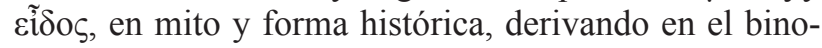
mio problemático de una "mitología" y de una "ideología". En efecto, la transformación del fracaso político de un "evento" del pasado en "signo" de eventos futuros se presenta ante el peligro de que ambos sean disociados y se confundan; la primacía del "signo" por sobre el "evento" portaría al eidos de una máscara trágica que ocultaría el significado del acontecimiento histórico ${ }^{53}$.

El análisis de Bloch supone, por tanto, un doble condicionamiento: la vida de Münzer queda reducida a concepto y determinada trágicamente a una sola causa y a un único fin; también, y más grave aún, la participación de la masa campesina queda hipostasiada y supeditada a una conceptualización subjetiva univoca ${ }^{54}$. Tanto los acontecimientos de la guerra como el principio espiritual articulador de toda revolución son condensados por Bloch en la trascendencia simbólica de un personaje devenido en mito.

Por un lado, la figuración trágica de Münzer es impugnada desde la concepción mítica que Benjamin le reserva al héroe trágico. En Bloch "el héroe trágico" no se define "por la perfección y esencialidad clasicistas, sino por ser alguien que padece y derrama su sangre" 55 . Este padecimiento aparece en Münzer en función de una tarea moral y políticamente colectiva. Para Benjamin, "la forma canónica de la vida mítica es precisamente la del héroe" y "de naturaleza mítica es por tanto toda representación en el ámbito moral del patriótico «uno para todos», hasta el sacrificio redentor", donde la vida del héroe culmina en el concepto de su "tarea" 56 .

\section{Ibidem, p. 61.}

Ibidem, p. 121

53 A. Infranca, "Para una lectura estética del Thomas Münzer de Ernst Bloch", en M. Vedda (comp.), Ernst Bloch. Tendencias y latencias de un pensamiento, Buenos Aires, Herramienta, 2007, pp. 113-115.

54 Este mecanismo de transformar un evento histórico en una hipóstasis subjetiva se combina con el procedimiento de homogeneizar períodos y contextos históricos completamente diferentes. Al referir al movimiento alemán de 1848, Bloch escribe: "Mas en esta relación se nos vuelven a aparecer, resplandecientes, la figura y el designio de Thomas Münzer, que en muchos aspectos nos recuerda a Liebknecht y cuya condición de organizador implacable llega a situarlo incluso en la vecindad de Lenin y su estirpe, además de infundir a la Revolución (...) su finalidad más pujante. Del hombre ruso, el más interiorizado de todos, dio Münzer una anticipación en su propia persona”. E. Bloch, Thomas Münzer, teólogo de la revolución, op. cit., p. 134.

55 M. Vedda, "Tragedia, actualidad, utopía. A propósito de las controversias entre el joven Lukács y el joven Bloch”, en Ernst Bloch. Tendencias y latencias de un pensamiento, op. cit., p. 102.

56 W. Benjamin, Obras, Libro I, vol. 1, R. Tiedemann y H. Schweppenhäuser (eds.), Madrid, Abada, 2006, p. 166.
Por otro lado y en relación a la hipóstasis de un acontecimiento histórico en una figura subjetiva o, a la inversa, la conversión de un personaje en eidos histórico, el segundo aspecto problemático se ubica en un plano metafísico. Partiendo de la figura de Münzer, la trasciende pero sólo para confirmar el mecanismo de su entronización. De este modo, Boch postula una interioridad como hacedora de la historia y de toda revolución, regida no sólo por los vectores ilustrados - principalmente kantianos-de la voluntad y la libertad, sino también por aquellos elementos espirituales relativos al inconsciente y las ensoñaciones:

Nacida con las cofradías laicas de los Hermanos del Va1le, promovida por Eckart y emergiendo progresivamente con Münzer, y los espiritualistas, se irguió el alma en sí propia, la libertad, en cuanto nuevo y último elemento de redención. (...) Y esta su revolucionaria magia del sujeto (...) se lleva enteramente a Dios hacia la esfera de lo más íntimo, hacia el prodigio de su propia imagen intuida, aún no consciente [noch ungewußten Ebenbildes], más allá de las cosas, del mundo y de Dios mismo. Tan en lo profundo residen, por último, el impulso [Antrieb] y el contenido de esta revolución, la más espiritual que hasta entonces conociera el mundo en amplitud ${ }^{57}$.

En un mismo movimiento, Bloch ubica esta interioridad espiritual como condición de posibilidad de la emancipación, al mismo tiempo que disocia el concepto de revolución de la agudización material de lógicas socio-económicas para comprenderlo como un proceso interno del alma. Este procedimiento de interiorización llega al punto más alto con el postulado de una "humanidad mística" [mystische Humanität $]^{58}$.

La idea de una subjetividad que desborda los límites de la consciencia constituye un distanciamiento de la concepción tradicional del sujeto; es ese resto de misticismo irracional el que permite introducir la contingencia en el marco del planteo de Bloch. Ahora bien, el componente trágico que acompaña la figuración de Münzer y el levantamiento campesino neutraliza el mismo potencial de esa espiritualidad inconsciente. En otras palabras, no hay compatibilidad teórica, al menos en sus consecuencias politicas, entre el designio fatalista de la vida de Münzer, determinado conceptualmente al escenario trágico del evento campesino, y el postulado de un espíritu revolucionario que interviene de forma contingente la coyuntura. La constelación trágica, en virtud de su circularidad y condicionamiento, torna impotente cualquier disrupción política en el escenario histórico.

Podría advertirse que la interioridad espiritual de Bloch está en sintonía con los residuos de gnosticismo en su obra que son fuertemente impugnados por Benja$\min ^{59}$. Como advierte Marchesoni, su aprobación a las "violentas críticas" de Salomo Friedlaender en la reseña de Espíritu de la utopía -titulada Der Antichrist und Ernst Bloch [1920]-respondería al rechazo de Benjamin

E. Bloch, Thomas Münzer, teólogo de la revolución, op. cit., p. 73. Cf. Ibidem, p. 246.

59 Los elementos gnósticos en el planteo blochiano pueden entreverse en su "fenomenología de preparación para acceder a Dios" [Phänomenologie der Gottbereitung]. Cf. Ibidem, pp. 222-223. 
a esta "metafísica de la interioridad" que reduce el evento redentor a un reencuentro del alma consigo misma ${ }^{60}$. En efecto, el principio de una interioridad del sujeto forma parte, desde la óptica benjaminiana, de la mitología fabricada por la Aufklärung. Disolver este principio así como extender el conocimiento hacia el ámbito religioso por la vía del lenguaje, es la tarea de la filosofía venidera que ya hacia finales de 1917 Benjamin identifica con la teología ${ }^{61}$.

Una de las múltiples potencialidades que Benjamin encuentra en la teología -en clara divergencia con Bloch- consiste en el vaciamiento de todo elemento intencional. En "La tarea del traductor" [1921], escrito el mismo año en que Bloch publica su obra, Benjamin introduce el concepto de "supervivencia" [Überleben] de una obra para pensar una instancia histórica que sobreviva más allá del sujeto: "podría hablarse de una vida o de un instante inolvidables [unvergeßlich], aun cuando toda la humanidad los hubiese olvidado"; si "su carácter exigiera que no pasase al olvido", ello no obtendría respuesta de los hombres sino más bien de una "esfera" asociada al "pensamiento divino"62.

Detrás de esta garantía divina de lo inolvidable aparece la concepción teológica del lenguaje de Benjamin. De acuerdo a ella, es el nombre - a diferencia de la "fenomenología" de Bloch- el que oficia de puente espiritual entre el ser humano y Dios ${ }^{63}$. Esta idea se inscribe en la tradición mística judía de exégesis bíblica con la cual Benjamin estuvo familiarizado en su juventud a través de Scholem ${ }^{64}$. Desde esta perspectiva, existe un abismo ontológico entre la palabra divina y cristalizada en el nombre y la palabra creada y finita del lenguaje humano, en tanto ésta nunca puede contener aquélla. La pregunta benjaminiana en "La tarea del traductor" refiere a la posibilidad de traducir a otro lenguaje los "residuos de inmediatez" propios del lenguaje original

60 S. Marchesoni, “Zur Vorgeschichte des Eingedenkens. Über Ernst Blochs «motorisch-phantastische Erkenntnistheorie» in Geist der Utopie und ihre «Umfunktionierung» bei Benjamin", en D. Weidner y S. Weigel (eds.), Benjamin-Studien 3, Paderborn, Wilhelm Fink, 2014, pp. 27-28. También Naishtat señala que la teología en Benjamin funciona como un "órganon herético, disimulado e invisible", en clara divergencia con la "interioridad de fe religiosa" al modo de Pascal o de Kierkegaard. Cf. F. Naishtat, "El órganon invisible. La gramática teológica del tiempo benjaminiano", Enrahonar 58, 2017, p. 17. Podría advertirse aquí que Jacob Taubes vincula precisamente la subjetividad espiritual del Thomas Münzer de Bloch con el tratamiento de Kierkegaard sobre la experiencia subjetiva religiosa. $\mathrm{Cf}$. J. Taubes, "Thomas Münzer, teología de la revolución”, Escatología occidental, Buenos Aires, Miño y Dávila, 2010, pp. 151-154.

61 Cf. W. Benjamin, Obras, Libro II, vol. 1, op. cit., p. 172. Esta idea de teología se retrotrae, según Ibarlucía, a su programa en torno a una "mística" y en oposición a la noción de "mito", tal como aparece en los escritos del período 1915-1916. Cf. R. Ibarlucía, "Sócrates, el presocrático. Walter Benjamin, la mitología y su lectura del Simposio en 1916", Eadem utraque Europa I, 1, 2005, pp. 183-192.

62 W. Benjamin, "La tarea del traductor", Angelus Novus, Barcelona, Edhasa, 1971, p. 128. Este núcleo inolvidable también aparece en su reseña sobre El idiota de Dostoievski [1921], cf. W. Benjamin, Obras, Libro II, vol. 1 op. cit., p. 243. Agamben explota esta exigencia benjaminiana de lo inolvidable para pensar una modalidad mesiánica del "impotencial" que no se cierre a la contingencia; este inolvidable sería lo que hace a la historia histórica y a la tradición transmisible. G. Agamben, El tiempo que resta, op. cit., pp. 47-49.

63 Cf. W. Benjamin, Obras, Libro II, vol. 1, op. cit., pp. 144-162.

64 W. T. Adorno, Sobre Walter Benjamin, Madrid, Cátedra, 2001, p. 18. que persisten en el lenguaje histórico ${ }^{65}$. Esta tarea de restitución a partir del nombre se presenta como mesiánica: consiste en juntar y reconstituir los fragmentos de la unidad del lenguaje originario que ha sido despedazada por la historia ${ }^{66}$.

La relación entre lenguaje y teología como medio de anulación de lo intencional también está presente en El origen del Trauerspiel alemán [1928], el escrito de habilitación de Benjamin que reúne sus reflexiones desde 1916 y marca el final de una etapa de su pensamiento. En la metodología delineada en el "Prólogo epistemocrítico", la investigación filosófica tiene por objeto las "ideas", cuyo modo de determinación no reside en la aprehensión consciente del entendimiento, sino en el "ser del nombre", un "ser aparatado de toda fenomenalidad" y "ausente de intención" en virtud de su conexión con la verdad. Aunque las ideas no son dadas a los fenómenos, tienen la función dialéctica de salvarlos [retten] y conservarlos en sus diferencias: es esta constelación benjaminiana entre idea y salvación la que está operando en la consumación mesiánica del tiempo histórico ${ }^{67}$.

Podría llevarse este intento de revocar lo intencional al plano de la redención que inicia el "Fragmento teológico-político": "Es el Mesías mismo quien sin duda completa todo acontecer histórico, y esto en el sentido de que es él quien redime [erlöst], quien completa [vollendet] y crea la relación del acontecer histórico con lo mesiánico mismo" 68 . En efecto, y a diferencia de Bloch, si el acontecimiento mesiánico no supone aquí una intervención necesaria por parte de un sujeto intencional es porque se trata de un asalto imprevisible y destructivo -y sólo por ello, político- que viene a consumar toda una época histórica.

La distancia decisiva entre los autores se juega en la reapropiación política que cada uno hace de la teología: si ella ingresa en Bloch a través de la dimensión espiritual y revolucionaria de la subjetividad, en el joven Benjamin la vía teológica es utilizada para desactivar, en un plano lingüístico, gnoseológico e histórico, el componente intencional.

No obstante, ello no implica la supresión de toda subjetividad en el planteo de Benjamin. Ricardo Ibarlucía analiza las tres formas del tiempo histórico presentes en sus escritos de juventud y deriva tres imágenes de la subjetividad: el "héroe como genio moral de la tragedia", el "mártir estético del Trauerspiel" y el "carácter destructivo" que asume las fuerzas mesiánicas y convierte las exigencias profanas en "nihilismo político" $"$.

65 M. Bröcker, "Lenguaje”, en E. Wizisla y M. Opitz (comps.), Conceptos de Walter Benjamin, Buenos Aires, Las cuarenta, 2014, p. 739.

66 El aspecto mesiánico reaparece con la noción judía de "tikkun" a la que se refirió con anterioridad: el momento utópico es representado "al comienzo del mito luriano como «rotura de las vasijas»". G. Scholem, Conceptos básicos del judaísmo, op. cit., p. 112. Benjamin alude a este mito al delinear la labor de la traducción como una reconstitución de los "fragmentos" del lenguaje divino, en analogía con el "volver a juntar los fragmentos de una vasija rota". W. Benjamin, "La tarea del traductor", op. cit., p. 139.

W. Benjamin, Obras, Libro I, vol. 1, op. cit., pp. 230-232.

Ibidem, Libro II, vol. 1, op. cit., p. 206.

${ }_{69}$ R. Ibarlucía, "Sein-Zeit und Jetztzeit: Benjamins Kritik an Heidegger in neuer Perspektive", en W. Bolle y H. Galle (eds.), Akten des XI. 
Esta última imagen de la subjetividad está en íntima conexión con el anarquismo político del joven Benjamin. La teoría de la catástrofe que está a la base del tiempo mesiánico enfatiza su naturaleza impredecible: "el Mesías no puede ser preparado", "viene de pronto, sin anunciarse, justo cuando menos se le espera o cuando se ha perdido ya hace mucho la esperanza"70. Precisamente en este instante catastrófico es posible situar su dimensión subjetiva: el carácter repentino y de confusión de ese momento conduce al sujeto benjaminiano a una "especie de estasis" que no sólo contrasta con el "momento de la decisión" propio del sujeto político de Bloch, sino que, desde la perspectiva crítica de Benjamin, ese momento blochiano formaría parte de la constelación mítica de la tragedia ${ }^{71}$.

\section{Consideraciones finales}

A partir de lo expuesto, podrían reunirse los apartados de historia y subjetividad para llevar la teología al ámbito profano de lo político. Podría concluirse, en primer lugar, lo siguiente: en el joven Benjamin la política no permanece atada ni a un voluntarismo, ni a una interioridad, ni al decisionismo propio de la República de Weimar, sea bajo la soberanía schmittiana y la Konservative Revolution o como respuesta marxista ante la crisis en la línea de Bloch. Lo político recae más bien en el momento destructivo de la tensión dialéctica que se juega en cada acontecimiento y que constituye el signo originario de la historia. Su nihilismo, traducido en anarquismo teocrático, conduce a Benjamin a rechazar cualquier compromiso o instancia política de organización y aceptar sólo la violencia divina y destructiva. Aun dejando de lado este posicionamiento, $\mathrm{y}$ atendiendo al giro inminente que lo conducirá al marxismo, la propuesta de una praxis subjetiva continúa en un plano dialéctico de tensión. Como afirma Adorno, Benjamin "no se dirige contra el subjetivismo supuestamente hinchado, sino contra el concepto mismo de lo subjetivo"72.

En segundo lugar, tal como se expuso, Bloch asume el ejemplo contemporáneo de la revolución bolchevique y propone la instauración marxista de una sociedad sin clases por la vía espiritual de una praxis del sujeto histórico. Ahora bien, las dificultades de su historiografía pueden explicarse en virtud de la dirección política de su programa. La disrupción histórica propia de la tradición que busca salvar es la misma que sacrifica en virtud de un postulado metafísico que iguala y suprime la singularidad cualitativa de cada acontecimiento. Este principio transhistórico es precisamente la subjetividad espiritual que conduciría el curso histórico al advenimiento revolucionario.

Podría estimarse que los puntos conflictivos del Thomas Münzer se desprenden de una impostura teórica en favor del posicionamiento político de Bloch. Frente a la urgencia de encontrar una salida a lo que Benjamin interpretaba como el "mito" del capitalismo, Bloch "siente la necesidad de confiarse a los mitos y símbolos para mantener viva la esperanza de una futura, pero inminente, revolución mundial"73. En efecto, a partir del gesto blochiano de construir el mito de la tradición revolucionaria para salir del mito del parásito capitalista, podría preguntarse: ¿es posible salir del mito sin crear simultáneamente otro ${ }^{74}$
Lateinamerikanischen Germanistenkongresses, vol. 1, Edusp, San Pablo, 2005, p. 287.

70 G. Scholem, Conceptos básicos del judaísmo, op. cit., p. 110.

71 I. Boldyrev, Ernst Bloch and His Contemporaries. Locating Utopian Messianism, op. cit., p. 135.
72 W. T. Adorno, Sobre Walter Benjamin, op. cit., p. 20. Para otras alusiones: Ibidem, pp. 14, 24, 26, 41 y 46.

73 A. Infranca, "Para una lectura estética del Thomas Münzer de Ernst Bloch", op. cit., p. 115.

74 En ocasión de la "Rehabilitierung del mito" propuesta por Habermas, aunque direccionada no ya hacia la derecha sino hacia la izquierda, Esposito advierte: "Daría la sensación de que el Entmythologisieren no puede acontecer (...) si no es en un nuevo mythisieren o, como desde otra perspectiva se observó, que un pensamiento explícitamente comprometido en desmitificar puede funcionar sólo mediante un nuevo «tropismo mítico»". R. Esposito, "Mito", Diez pensamientos acerca de la política, Buenos Aires, FCE, 2012, p. 157. 


\section{Bibliografía}

Adorno, W. T., Sobre Walter Benjamin, trad. Carlos Fortea, Madrid, Cátedra, 2001.

Agamben, G., El tiempo que resta. Comentario a la carta a los Romanos, trad. Antonio Piñero, Madrid, Trotta, 2006.

Benjamin, W., "La tarea del traductor", Angelus Novus, trad. H.A Murena, Barcelona, Edhasa, 1971, pp. 127-143.

-, Gesammelte Briefe I, G. Scholem y T. W. Adorno (eds.), Frankfurt am Main, Suhrkamp, 1978.

-, Gesammelte Schriften, Bände I-VII, R. Tiedemann y H. Schweppenhäuser (eds.), Frankfurt am Main, Suhrkamp, 1991.

-, La dialéctica en suspenso. Fragmentos sobre historia, trad. P. Oyarzun, Santiago de Chile, ARCIS-LOM, 2005.

-, Obras, Libro I, vol. 1, R. Tiedemann y H. Schweppenhäuser (eds.), Madrid, Abada, 2006.

-, Obras, Libro II, vol. 1, R. Tiedemann y H. Schweppenhäuser (eds.), Madrid, Abada, 2007.

-, "El capitalismo como religión. Introducción por Enrique Foffani y Juan Antonio Ennis", Katatay X, 13/14, 2016, pp. 178191.

Berdet, M., "La trilogía política”, en P. Oyarzun, C. Pérez López y F. Rodríguez (eds.), Letal e incruenta. Walter Benjamin y la crítica de la violencia, Santiago de Chile, LOM, 2017, pp. 51-78.

Bloch, E., Thomas Münzer als Theologe der Revolution, München, Kurt Wolff, 1921.

-, Thomas Münzer, teólogo de la revolución, trad. J. Deike Robles, Madrid, Ciencia Nueva, 1968.

Boldyrev, I., Ernst Bloch and His Contemporaries. Locating Utopian Messianism, Londres/New York, Bloomsbury, 2014.

Bröcker, M., "Lenguaje", en E. Wizisla y M. Opitz (comps.), Conceptos de Walter Benjamin, trad. M. E. Belforte y M. Vedda, Buenos Aires, Las cuarenta, 2014, pp. 709-759.

Deuber-Mankowsky, A., "Walter Benjamin's Theological-Political Fragment as a response to Ernst Bloch's Spirit of Utopia", Leo Baeck Institute Yearbook 47/1, 2002, pp. 3-20.

Esposito, R., "Mito", Diez pensamientos acerca de la política, trad. L. Padilla López, Buenos Aires, Fondo de Cultura Económica, 2012, pp. 141-167.

Fenves, P., The Messianic Reduction. Walter Benjamin and the Shape of Time, California, Stanford University Press, 2011.

Hamacher, W. y K. Wetters, "Guilt History: Benjamin’s Sketch «Capitalism as Religion»”, Diacritics 32, 3/4, The Johns Hopkins University Press, 2002, pp. 81-106.

Ibarlucía, R., "Sein-Zeit und Jetztzeit: Benjamins Kritik an Heidegger in neuer Perspektive", en W. Bolle y H. Galle (eds.), Akten des XI. Lateinamerikanischen Germanistenkongresses, vol. 1, São Paulo, Edusp, 2005, pp. 279-292.

-, "Sócrates, el presocrático. Walter Benjamin, la mitología y su lectura del Simposio en 1916", Eadem utraque Europa I, 1, 2005, pp. 182-201.

Infranca, A., "Para una lectura estética del Thomas Münzer de Ernst Bloch", en M. Vedda (comp.), Ernst Bloch. Tendencias y latencias de un pensamiento, Buenos Aires, Herramienta, 2007, pp. 111-118.

Kohlenbach, M., "Religion, Experience, Politics: On Erich Unger and Walter Benjamin”, en M. Kohlenbach y R. Geuss (eds.), The Early Frankfurt School and Religion, Londres/New York, Palgrave Macmillan, 2005, pp. 64-84.

Löwy, M., Walter Benjamin: aviso de incendio. Una lectura de las tesis "Sobre el concepto de historia", trad. H. Pons, Buenos Aires, Fondo de Cultura Económica, 2012.

-, Redención y utopía. El judaísmo libertario en Europa central, trad. de H. Tarcus, Santiago/Chile, Ariadna Ediciones, 2018.

Marchesoni, S., "Zur Vorgeschichte des Eingedenkens. Über Ernst Blochs «motorisch-phantastische Erkenntnistheorie» in Geist der Utopie und ihre «Umfunktionierung» bei Benjamin”, en D. Weidner y S. Weigel (eds.), Benjamin-Studien 3, Paderborn, Wilhelm Fink, 2014, pp. 15-29.

Munster, A., “Ernst Bloch et Walter Benjamin: éléments d'analyse d'une amitié difficile”, L'Homme et la société 69-70, 1983, pp. 55-77.

Naishtat, F., "Catástrofe y esperanza. Pensar un presente barroco a partir de Benjamin y Bloch", en E. Jozami, A. Kaufman, y M. Vedda (comps.), Walter Benjamin en la ex ESMA, Buenos Aires, Prometeo, 2013, pp. 251-268.

-, "El órganon invisible. La gramática teológica del tiempo benjaminiano", Enrahonar 58, 2017, pp. 13-31.

Rabinbach, A., In the Shadow of Catastrophe. German Intellectuals Between Apocalypse and Enlightenment, Berkeley/Los Angeles/London, University of California Press, 1997.

Sagnol, M., Tragik und Trauer. Walter Benjamin, Archäologe der Moderne, Berlin, Kadmos, 2017.

Scholem, G., Walter Benjamin. Historia de una amistad, trad. J. F. Yvars y V. Jarque, Barcelona, Península, 1987.

-, Conceptos básicos del judaísmo, trad. de J. L. Barbero, Madrid, Trotta, 2008.

Steiner, U., Walter Benjamin, Stuttgart/Weimar, J.B. Metzler, 2004.

-, "Kapitalismus als Religion. Anmerkungen zu einem Fragment Walter Benjamins", Deutsche Vierteljahrsschrift für Literaturwissenschaft und Geistesgeschichte, Band 72, 1998, pp. 147-171

Taubes, J., “Thomas Münzer, teología de la revolución”, Escatología occidental, Buenos Aires, Miño y Dávila, 2010, pp. 140154.

Vargas, M., “Comentario a «Capitalismo como religión» de Walter Benjamin”, en F. Naishtat, E. G. Gallegos y Z. Yébenes (eds.), Ráfagas de dirección múltiple. Abordajes de Walter Benjamin, México, Universidad Autónoma Metropolitana, 2014, pp. 377-406.

Vedda, M., “Tragedia, actualidad, utopía. A propósito de las controversias entre el joven Lukács y el joven Bloch”, Ernst Bloch. Tendencias y latencias de un pensamiento, Buenos Aires, Herramienta, 2007, pp. 97-110. 